\title{
Comparison analysis of pollutant emissions factor for Lantan combustion instead of raw coal
}

\author{
Jili Hou ${ }^{1, a}$, Wenzhi Shang ${ }^{2, b}$, Junli Liü ${ }^{2, c}$, Yue Ma ${ }^{1, d}$, Jian Shi ${ }^{1, e}$, Shuyuan $\mathrm{Li}^{1, \mathrm{f}, *}$, \\ Jinsheng Teng ${ }^{3, g}$ \\ ${ }^{1}$ China University of Petroleum-Beijng, Beijing 102249, China; \\ ${ }^{2}$ Shenmu Sanjiang Coal Chemical Industry Co., LTD, Shenmu 719399, China; \\ ${ }^{3}$ Shandong Energy Longkou Mining Group Co., LTD, Longkou 265700, China. \\ awww.houjili@126.com, bswz3858@sohu.com, \\ c373596508@qq.com, 'dmayue198417@163.com, ${ }^{\text {c } 403643995 @ q q . c o m, ~}{ }^{f}$ syli@cup.edu.cn, ${ }^{9}$ lkjttjs \\ @126.com.
}

Keywords: coal, semi-coke, combustion, emission factor, $\mathrm{SO}_{2}$, $\mathrm{NOx}, \mathrm{PAHs}$.

\begin{abstract}
Volatiles, sulfur, nitrogen and other impurity atoms have released in the process of bituminous coal retorting and high-quality Lantan can be obtained. In order to investigate the feasibility of Lantan to combustion as a clean fuel instead of raw coal, this paper selects several representative coals in different areas for burning and testing the main pollutant emissions factor. Result show that the PM 2.5 emissions of Lantan is about $3.23 \%$ of coal, $\mathrm{SO}_{2}$ emissions reduced by $60 \%$, PAHs emissions reduced by more than $97 \%$ which is the most harmful to the body. Burning Lantan has a significant effect for reducing haze if used as civilian fuel instead of raw coal.
\end{abstract}

\section{Introduction}

Lantan is the low-volatility solid carbonaceous product of the pyrolysis of high-volatility non-viscous or low viscous bituminous coal with a low temperature. Coal tar and retorting gas can also be obtained [1, 2]. Lantan has several high quality characteristics, such as low-ash, low-sulfur, low-phosphorus, low-aluminum, high fixed-carbon, high chemical reactivity and high specific resistance. Moreover, the price of Lantan is comparatively cheaper than coke and anthracite coal. Therefore, Lantan has been gradually replaced the role of the coke and widely used in the fields of iron alloy, calcium carbide, fertilizer and gas generating, and above all it can be used as a civilian clean fuel for reducing haze efficiently [3].

In this paper, proximate analysis, ultimate analysis of coal samples and experimental analysis of their main combustion pollutant emission factor were conducted. The pollutant emission factor is as follows: (1)PM2.5, TC, OC, EC; (2) $\mathrm{SO}_{2}$, NOx; (3)PAHs, Alkanes.

\section{Basic properties analysis of Lantan and typical types of coal}

The coal samples used in this study was obtained from Shenmu, Shanxi and Ningxia province. The results of proximate analysis, ultimate analysis and heat value are given in Table 1 . The samples was crushed and screened to $0-0.2 \mathrm{~mm}$ particles before using. The analysis above was performed using an HTGF-3000 analyzer (Thailand), ZDHW-A8 analyzer and LECO CHN-2000 analyzer, respectively.

Table 1 Basic properties analysis of Lantan and typical coal samples

\begin{tabular}{cccccccc}
\hline \multirow{2}{*}{ Sample } & \multicolumn{4}{c}{ Proximate analysis (\%) } & \multirow{2}{*}{ N (\%) } & \multirow{2}{*}{ S (\%) } & $\begin{array}{c}\text { Heat value, } \\
\text { MJ } / \mathrm{kg}\end{array}$ \\
\cline { 2 - 5 } & $\mathrm{M}, \mathrm{ad}$ & $\mathrm{V}, \mathrm{d}$ & $\mathrm{A}, \mathrm{d}$ & $\mathrm{FC}, \mathrm{d}$ & & & 26.87 \\
Lantan & 8.45 & 7.99 & 11.17 & 80.84 & 0.80 & 0.36 & 28.16 \\
Bituminous coal & 11.40 & 37.28 & 7.80 & 54.92 & 0.90 & 0.33 & 21.90 \\
Shanxi & 2.22 & 6.16 & 11.26 & 82.58 & 0.99 & 0.40 & 33.26 \\
Ningxia & 2.30 & 9.51 & 6.45 & 84.04 & 0.65 & 0.36 & \\
\hline
\end{tabular}




\section{Comparison analysis of pollutant emissions factor for coal samples combustion}

Comparison analysis on PM2.5 and components of carbon emissions factor.

This paper selects Shenmu bituminous coal (BC), lump coal washing (LCW), Fuyou Lantan (FYLT), Tianyuan Lantan (TYLT), Ningxia anthracite coal (NXAC), Shanxi anthracite coal (SXAC) as research object. We can see from Fig. 1, PM2.5 emissions factor of Lantan and anthracite coal are far below bituminous coal and lump coal washing [4]. Fuyou and Tianyuan Lantan have reduced by $93.27 \%$ and $95.59 \%$, respectively, which is a little more than Shanxi anthracite coal, 1/2 and 1/3 of Ningxia anthracite coal, respectively.

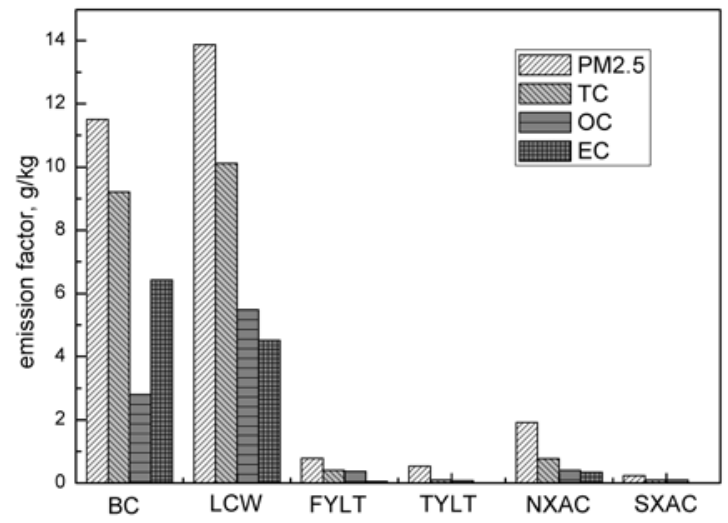

Fig. 1 Comparison analysis on PM2.5 and components of carbon emissions factor of coal samples

Comparison analysis of $\mathrm{SO}_{2}$ and $\mathrm{NOx}$ emissions factor.

As shown in Fig. 2, $\mathrm{SO}_{2}$ emission factor of Fuyou Lantan is the lowest and bituminous coal and Shanxi anthracite coal is the highest [5]; there is no significant differences between lump coal washing, Tianyuan Lantan and Ningxia anthracite coal; Fuyou Lantan is reduced by $60 \%$ relative to raw coal, and is $1 / 3$ and $1 / 2$ of Shanxi anthracite coal and Ningxia anthracite coal, respectively. This is mainly due to the way of coke water quenching which could completely avoid the situation of coke waste water quenching polluting Lantan again that caused by traditional ammonia coke quenching.

For NOx, there is no good clear effect of the emission reduction for burning Lantan [6], this could be because of the reduction is not obvious for that there are still more than $85 \%$ of the nitrogen kept in Lantan after a low temperature retorting; in addition, an incomplete combustion is another factor due to the combustion process is affected by combustion temperature, oxygen condition and other aspects of uncertainty.

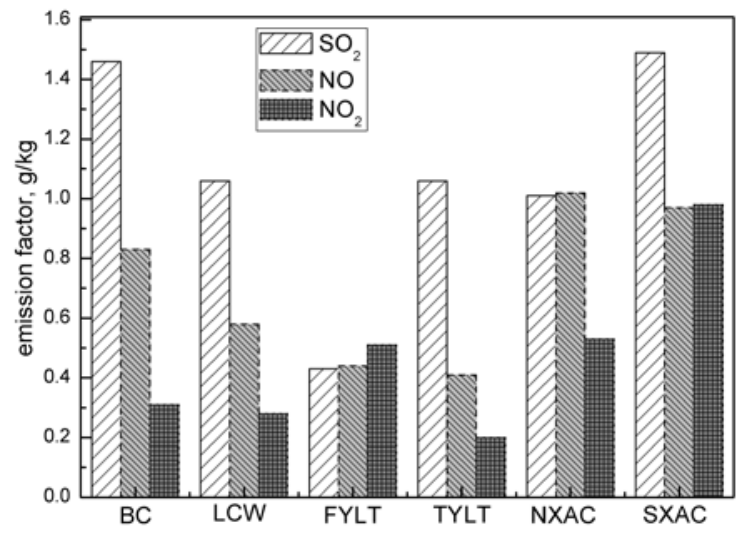

Fig. 2 Comparison analysis of $\mathrm{SO}_{2}$ and NOx emissions factor of coal samples

\section{Analysis of the sum of 20 kinds of PAHs and Alkanes emissions factor.}

On the emission of PHAs which is great harm to people's health [7], the sum of 20 kinds of PAHs emission factor of Shanxi anthracite coal, Lantan from Tianyuan and Fuyou is at a very low level, and of which, Lantan from Tianyuan is reduced by $99.96 \%$ that is close to Shanxi anthracite coal and is 1/254 of Ningxia anthracite coal. It is because of the coal tar was taken off first and then 
further remove macromolecular organic compounds in the process of Lantan production.

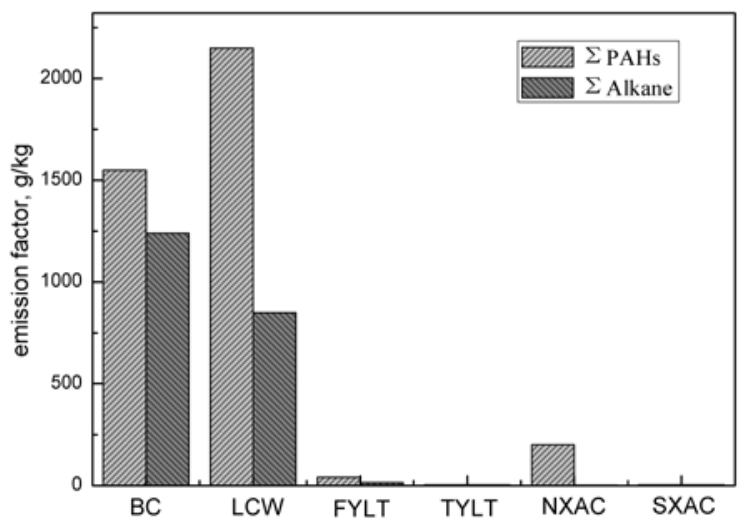

Fig. 3 Comparison analysis of PAHs and Alkanes emissions factor of coal samples

In 2013, civilian and scattered coal consumption was about 44.24 million tons, from this computative, first emissions of PM2.5 can reduce more than 500,000 tons and $\mathrm{SO}_{2}$ emissions can cut about 250,000 tons by substituting Lantan for bituminous coal; first emissions of PM2.5 can reduce nearly $1 / 2, \mathrm{SO}_{2}$ emissions can cut about 200,000 400,000 tons and PAHs can reduce by $60,000 \sim 80,000$ t by substituting Lantan for anthracite coal.

\section{Summary}

1. Lantan is the retorting product of qualified Shenmu bituminous coal. With a low temperature pyrolysis process and after a large number of volatile released, the harmful elements are greatly reduced but still kept the characteristics of coal. The indicators are better of Lantan than that of bituminous coal and part of anthracite coal.

2. Emission factor of PM2.5, $\mathrm{SO}_{2}$, PHAs and Alkanes of Lantan combustion are all far lower than that of bituminous coal and close to anthracite coal or even superior, which has a significant effect for reducing haze. Using Lantan as civilian fuel has evident emission reduction advantages instead of raw coal.

3. Due to the characteristics of low sulfur, low harmful elements and high heat value, Lantan has obvious environmental protection and economic for the application of steel and building material industry sector.

\section{Acknowledgements}

This research was supported by the special projects of Taishan scholar construction work (ts20120518).

\section{References}

[1]. Cengceng Geng, Shuyuan Li, Changtao Yue, et al. Pyrolysis characteristics of bituminous coal. Journal of the Energy Institute. Vol. xxx (2015), p. 1-6.

[2]. Zhiping Mi, Ningbo Wang. Actuality and progress of coal retorting with a low temperature. Clean coal technology. Vol. 16 (2010) No. 2, p. 33-37. (In Chinese)

[3]. Xin Zhang. Study of high efficiency and clean utilization for Lantan instead of anthracite. Clean coal technology. Vol. 21 (2015) No. 3, p. 103-106. (In Chinese)

[4]. Yingjun Chen, Chongguo Tian, Yanli Feng, et al. Measurements of emission factors of PM2.5, OC, EC, and BC for household stoves of coal combustion in China. Atmospheric Environment. Vol. 109 (2015), p. 190-196.

[5]. Rui Wang, Zhian Mo, Yulong Liu. Migration analysis of sulfur during Lantan production 
process. Industrial safety and environment protection. Vol. 40 (2014) No. 7, p. 61-64. (In Chinese)

[6]. Cheoreon Moon, Yonmo Sung, Seongyong Eom, et al. NOx emissions and burnout characteristics of bituminous coal, lignite, and their blends in a pulverized coal-fired furnace. Experimental Thermal and Fluid Science. Vol. 62 (2015), p. 99-108.

[7]. Jie Dong, Zhu Cheng, Fan Li. PAHs emission from the pyrolysis of Western Chinese coal. Journal of Analytical and Applied Pyrolysis. Vol. 104 (2013), p. 502-507. 